\title{
Effect of Diabetes Mellitus on Frequency of Adverse Events in Patients With Acute Coronary Syndromes Undergoing Percutaneous Coronary Intervention
}

\author{
Raffaele Piccolo, MD ${ }^{\mathrm{a}}$, Anna Franzone, $\mathrm{MD}^{\mathrm{a}}$, Konstantinos C. Koskinas, $\mathrm{MD}^{\mathrm{a}}$, Lorenz Räber, MD, PhD ${ }^{\mathrm{a}}$, \\ Thomas Pilgrim, MD ${ }^{\mathrm{a}}$, Marco Valgimigli, MD, PhD ${ }^{\mathrm{a}}$, Stefan Stortecky, MD ${ }^{\mathrm{a}}$, Julie Rat-Wirtzler, MSc ${ }^{\mathrm{b}}$, \\ Sigmund Silber, $\mathrm{MD}^{\mathrm{c}}$, Patrick W. Serruys, $\mathrm{MD}^{\mathrm{d}}$, Peter Jüni, $\mathrm{MD}^{\mathrm{e}, \mathrm{f}}$, Dik Heg, PhD ${ }^{\mathrm{b}, \mathrm{g}}$, and \\ Stephan Windecker, $\mathrm{MD}^{\mathrm{a}, *}$
}

\begin{abstract}
Few data are available on the timing of adverse events in relation to the status of diabetes mellitus and the type of acute coronary syndrome (ACS). We investigated this issue in diabetic and nondiabetic patients admitted with a diagnosis of non-ST-segment elevation ACS (NSTE-ACS) or ST-segment elevation myocardial infarction (STEMI) undergoing percutaneous coronary intervention. Patient-level data from 6 studies $(n=16,601)$ were pooled and only patients with ACS are included $(n=9,492)$. Early ( 0 to 30 days), late (31 to 365 days), and overall ( 0 to 365 days) events were analyzed. Diabetes mellitus was present in 1,927 patients (20.3\%). At 1 year, all-cause mortality was highest for diabetic patients with STEMI (13.4\%), followed by diabetic patients with NSTE-ACS (10.3\%), nondiabetic patients with STEMI (6.4\%) and nondiabetic patients with NSTE-ACS (4.4\%; $\mathrm{p}<0.001)$. Among patients with diabetes, there was a significant interaction $(p<0.001)$ for STEMI versus NSTE-ACS in early compared with late mortality, due to an excess of early mortality associated with STEMI (9.3\% vs 3.7\%; hazard ratio $2.31,95 \%$ CI 1.52 to $3.54, \mathrm{p}<0.001)$. Compared with diabetic NSTE-ACS patients, diabetic patients with STEMI had an increased risk of early stent thrombosis (hazard ratio $2.26,95 \%$ CI 1.48 to $3.44, p<0.001$ ), as well as a significant interaction $(p=0.009)$ in the risk of target lesion revascularization between the early and late follow-up. The distribution of fatal and nonfatal events according to the type of ACS was not influenced by diabetic status. In conclusion, diabetes in ACS setting confers a worse prognosis with 1-year mortality $>10 \%$ in both STEMI and NSTE-ACS. Notwithstanding the high absolute rates, the temporal distribution of adverse events related to the type of ACS is similar between diabetic and nondiabetic patients.
\end{abstract}

Diabetes mellitus (DM) is a common clinical condition and a serious global health problem. During the last 2 decades, the incidence and prevalence of DM have grown at exponential rates worldwide, and by 2035, the global prevalence is expected to further increase by more than $50 \%$ compared with 2013 estimates. ${ }^{1}$ Although the incidence of acute myocardial infarction (MI), which represents the most common diabetes-related complication, has steadily decreased by $68 \%$ from 1990 to 2010 , the reduction in

\footnotetext{
${ }^{a}$ Department of Cardiology, Bern University Hospital, University of Bern, Bern, Switzerland; ${ }^{b}$ Institute of Social and Preventive Medicine, Clinical Trials Unit, University of Bern, Bern, Switzerland; ${ }^{\mathrm{c} D e p a r t m e n t}$ of Cardiology, Heart Center at the Isar, Munich, Germany; ${ }^{\mathrm{d}}$ International Centre for Circulatory Health, Imperial College London, London, United Kingdom; ${ }^{\mathrm{e}}$ Institute of Primary Health Care, University of Bern, Bern, Switzerland; ${ }^{\mathrm{f}}$ Department of Medicine, Applied Health Research Centre (AHRC), Li Ka Shing Knowledge Institute of St. Michael's Hospital, University of Toronto, Toronto, Canada; and ${ }^{g}$ Department of Clinical Research, Clinical Trials Unit, University of Bern, Bern, Switzerland. Manuscript received March 10, 2016; revised manuscript received and accepted May 4, 2016.

*Corresponding author: Tel: (+41) 31-632-44-97; fax: $(+41)$ 31-63211-31.

E-mail address: stephan.windecker@insel.ch (S. Windecker).
}

absolute terms remains negligible due to the increase in life expectancy and population growth. ${ }^{2}$

Several studies have demonstrated that the temporal distribution of adverse events in patients with acute coronary syndrome (ACS) is determined by the type of ACS. ${ }^{3-5}$ Typically, the risk of mortality in patients with ST-segment elevation MI (STEMI) is highest during the first 30 days and then attenuates over time. This pattern is at variance with patients affected by non-ST-segment elevation ACS (NSTE-ACS), who commonly feature a higher risk of recurrent ischemic events during the longer-term follow-up. Although it is well established that DM confers an impaired prognosis in the setting of $\mathrm{ACS},{ }^{6-10}$ it remains unclear whether DM affects the temporal pattern of adverse events in patients with ACS undergoing percutaneous coronary intervention (PCI). Therefore, the purpose of this study was to determine the timing of mortality and other nonfatal adverse events according to diabetic status and type of ACS (STEMI vs NSTE-ACS) by pooling data from contemporary cohorts of patients undergoing PCI.

\section{Methods}

We pooled individual patient data from 5 randomized clinical trials and the Bern PCI Registry, which were 
Table 1

Baseline clinical characteristics

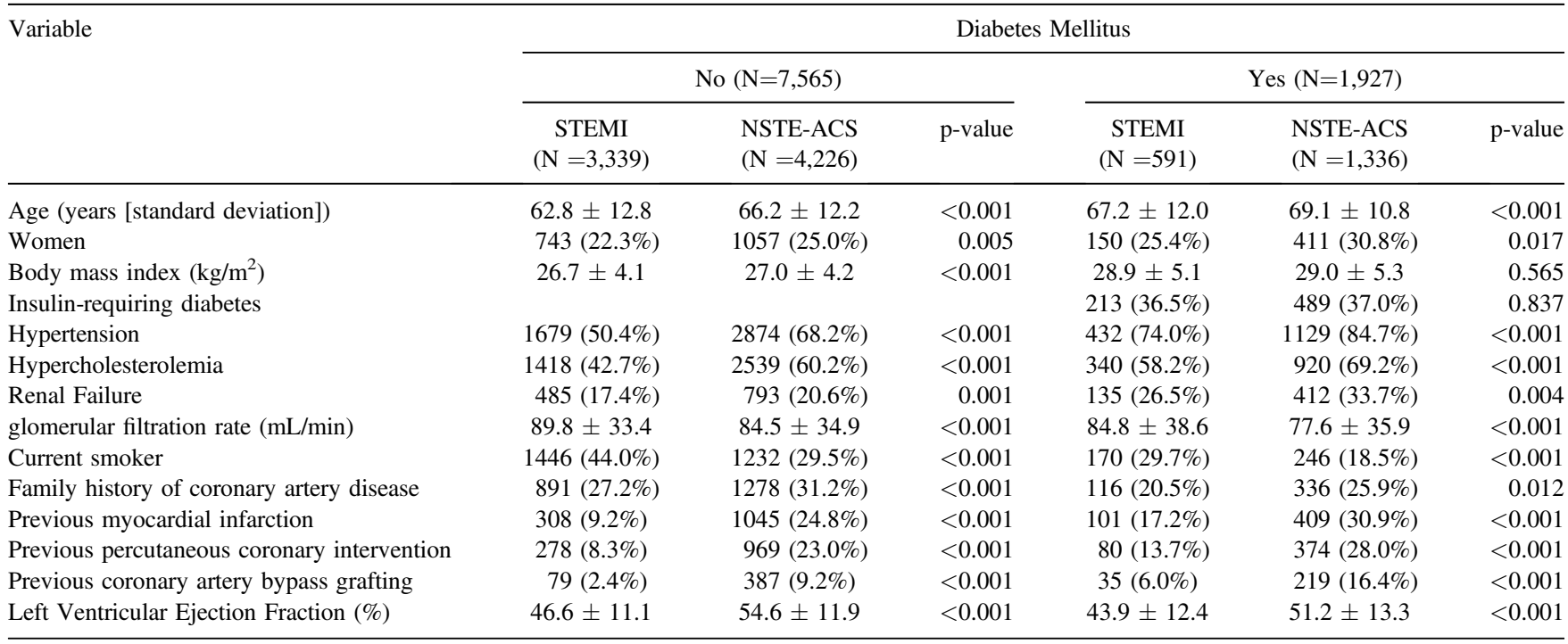

conducted from 2004 to 2014 at European institutions. The SIRTAX (Sirolimus-Eluting and Paclitaxel-Eluting Stent for Coronary Revascularization-NCT00297661), ${ }^{11}$ the LEADERS (Limus Eluted from A Durable Versus Erodable Stent coating-NCT00389220), ${ }^{12}$ the RESOLUTE (Randomized Comparison of a Zotarolimus-Eluting Stent with an Everolimus-Eluting Stent for Percutaneous Coronary Intervention-NCT00617084) ${ }^{13}$ and the BIOSCIENCE (Ultrathin Strut Biodegradable Polymer Sirolimus-Eluting Stent Versus Durable Polymer Everolimus-Eluting Stent for Percutaneous Coronary Revascularization-NCT01443104) ${ }^{14}$ are all-comers trials comparing different drug-eluting stents strategies. The PRODIGY (Prolonging Dual Antiplatelet Treatment After Grading Stent-Induced Intimal Hyperplasia Study) trial (NCT00611286) is a 4-by-2 randomized study, in which patients were assigned to a balanced mixture of stents and to different durations of dual antiplatelet therapy (6 or 24 months). ${ }^{15}$ Details on study design and trial results were reported elsewhere. ${ }^{11-13,15,16}$ Briefly, all patients were eligible if they had at least 1 lesion with a diameter stenosis $\geq 50 \%$ in a vessel with a reference diameter of $\geq 2.25 \mathrm{~mm}$. None of the randomized studies imposed any restriction with respect to the number of treated lesions, treated vessels, lesion length, or number of stents implanted. The Bern PCI Registry (NCT02241291) is a prospective registry including all consecutive patients undergoing PCI at the Bern University Hospital (Bern, Switzerland) with no formal exclusion criteria. For the purpose of the present study, we excluded patients with stable coronary artery disease as clinical presentation at the time of the index PCI.

All trials complied with the Declaration of Helsinki, and the study protocols were approved by the ethics committees at each study center. Patients had provided written, informed consent for participation in the individual studies.

Study participants were classified according to diabetic status at the time of the index PCI and stratified by ACS type (STEMI or NSTE-ACS). DM was defined as known
DM at the time of hospital admission and included also patients treated with diet only. The primary outcome of interest was all-cause mortality. Secondary outcomes included cardiac death, MI, definite and definite or probable stent thrombosis, target lesion and target vessel revascularization. End point definitions were comparable across the 6 studies and a clinical events committee independently adjudicated adverse events in all studies. Cardiac death was defined as death from cardiac causes or any death from unknown causes in the SIRTAX, ${ }^{11}$ LEADERS,${ }^{12}$ BIOSCIENCE,${ }^{16}$ PRODIGY trials, ${ }^{15}$ and the Bern PCI registry, and as any death unless an undisputed noncardiac cause was present in the RESOLUTE trial. ${ }^{13}$ MI was defined in the SIRTAX and LEADERS trials as the presence of new Q-waves in $\geq 2$ contiguous leads, or-in the absence of significant Q-waves-as an increase in the creatinine kinase level to more than twice the upper limit of the normal range with an elevated level of creatinine kinase-MB or troponin. ${ }^{11,12}$ In the RESOLUTE, ${ }^{13}$ BIOSCIENCE, ${ }^{16}$ and the Bern PCI registry, MI was defined according to the extended historical definition that is consistent with the one used in the SIRTAX and LEADERS trials. ${ }^{17}$ However, in the extended definition, the diagnosis of reinfarction in case biomarkers have not yet peaked requires new signs or clinical symptoms of myocardial ischemia accompanied by an additional $\geq 50 \%$ elevation of biomarkers of myocardial damage within 24 hours, whereas after the biomarker has peaked, any significant increase starting within the 48 hours after PCI defines a spontaneous MI. ${ }^{17}$ In the PRODIGY trial, the definition of MI was based on the detection of increase and/or decrease in creatine kinase-MB or troponin with at least 1 value above the upper limit of normal together with evidence of myocardial ischemia with at least 1 of the following: symptoms of ischemia; electrocardiographic changes indicative of new ischemia (new ST-T changes or new left bundle branch block); development of pathological Q-waves. ${ }^{15}$ Stent thrombosis was defined according to the Academic Research Consortium criteria. ${ }^{18}$ 
Table 2

Procedural characteristics and medication

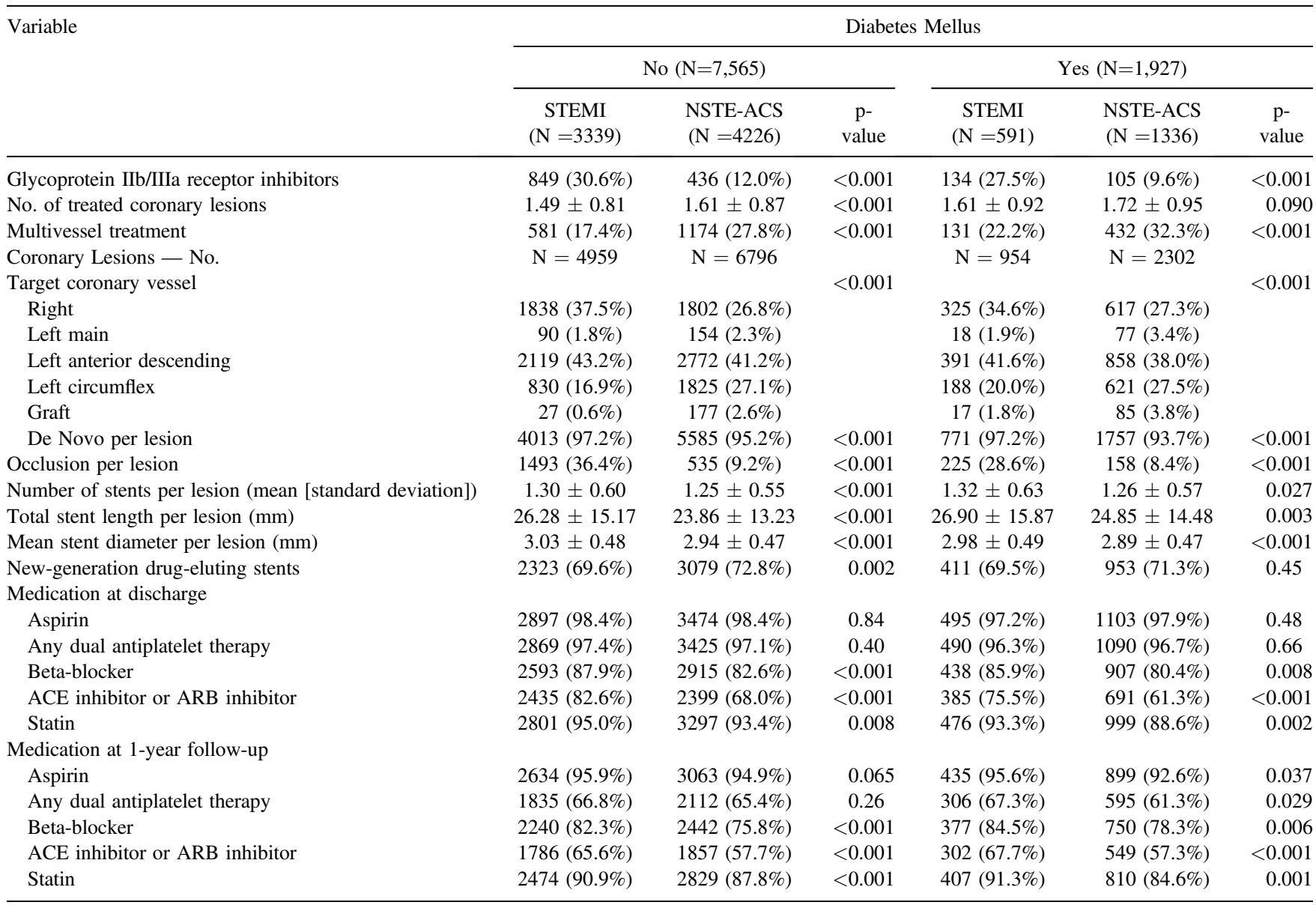

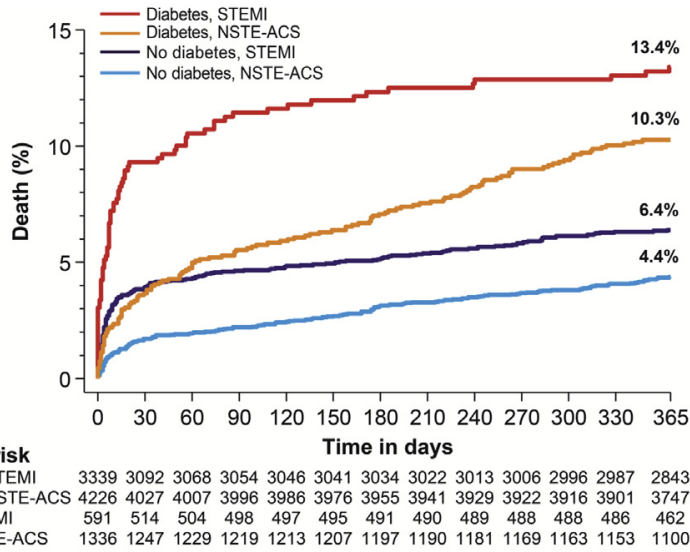

No diabetes, STEMI 3339309230683054304630413034302230133006299629872843 No diabetes, NSTE-ACS 4226402740073996398639763955394139293922391639013747

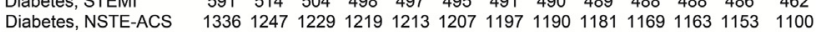

Figure 1. Kaplan-Meier time-to-event curves showing all-cause mortality at 1 year across the 4 study groups.

Data from the randomized trials were imported from original source files and managed using REDCap electronic data capture tools, ${ }^{19}$ whereas data from the Bern PCI registry were stored in a central database (Cardiobase, $2 \mathrm{mT}$; Ulm, Germany). All the data were hosted at the Clinical Trials Unit and Department of Cardiology of the University of
Bern (Bern, Switzerland). For the purpose of this study, we excluded all patients with stable coronary artery disease or in whom the diabetic status was missing. Continuous variables are presented as mean \pm SD and were compared with independent samples Student $t$ test. Categorical variables are expressed as counts and percentages and were compared with the chi-square or Fisher's exact tests as appropriate. Baseline lesion variables were analyzed using general or generalized linear mixed models, accounting for lesions nested within patients. Clinical outcomes at 1 year were expressed as counts with rates computed according to the Kaplan-Meier method. Cox regression analysis stratified by study was used to calculate hazard ratios (HRs) with $95 \%$ CIs. Adjusted HRs $\left(\mathrm{HR}_{\mathrm{adj}}\right)$ were derived from multiple imputation estimated Cox regressions (20 data sets created using chained equations and estimates combined used the Rubin's rule), adjusting for baseline variables associated with the primary outcome at the univariate analysis with significance level of $p<0.20$ (age, gender, body mass index, arterial hypertension, dyslipidemia, current smoker, previous MI, and a family history of coronary artery disease). The instantaneous risk of death was assessed with a flexible parametric survival model according to the method described by Lambert and Royston. ${ }^{20}$ Landmark analyses were done according to a prespecified landmark point at 
Table 3

Early, late, and overall mortality associated with diabetic status

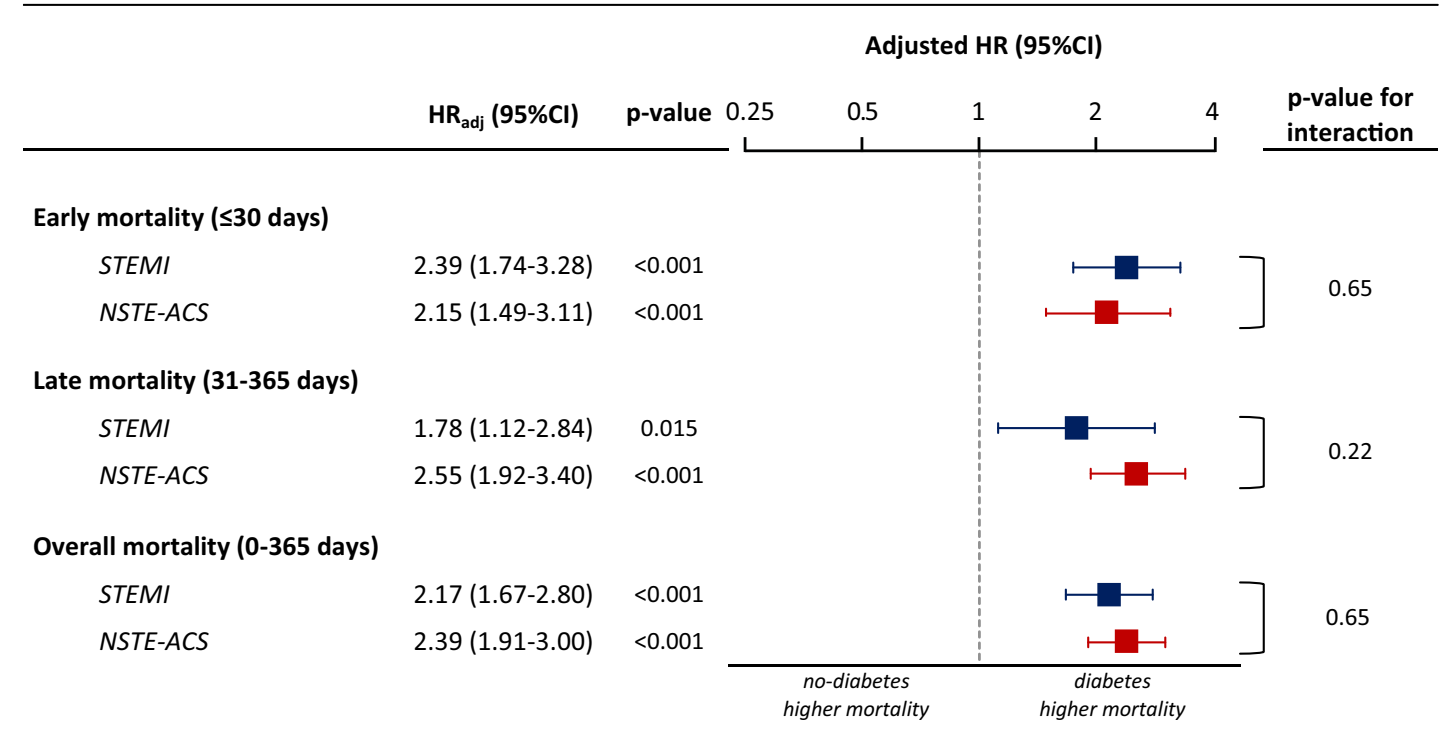

Adjusted hazard ratios from Cox regressions comparing diabetes versus nondiabetes, stratified by trial and adjusted for age, gender, body mass index, hypertension, hypercholesterolemia, smoker; history of coronary artery disease, myocardial infarction.

30 days, with HRs calculated separately for events up to 30 days, and between 31 to 365 days. For each type of event, patients were censored at the time of the first eventa patient who experienced an event contributing to a specific end point within 30 days, for example, was censored at the time of that event and excluded from the analysis after the landmark point. Finally, interaction tests were provided to evaluate the effect of DM on the outcomes of STEMI versus NSTE-ACS patients and to assess the timing of early and late events of STEMI compared with NSTE-ACS patients according to the presence of DM. All $\mathrm{p}$ values and CIs are 2 sided. A $p$ value $<0.05$ was considered statistically significant. All analyses were carried out with Stata Statistical Software, release 14 (StataCorp LP, College Station, Texas).

\section{Results}

The initial population consisted of 16,601 patients who underwent PCI. After the exclusion of patients with stable coronary artery disease $(n=7,057)$ or in whom diabetic status was unknown $(n=52)$, a total of 9,492 patients with ACS undergoing PCI were included in the current analysis. DM was present in 1,927 patients (20.3\%), of whom 591 patients $(30.7 \%)$ presented with STEMI and 1,336 patients (69.3\%) with NSTE-ACS. Among 7,565 patients without DM, STEMI and NSTE-ACS were present in 3,339 (44.1\%) and 4,226 (55.9\%) cases, respectively. Baseline characteristics for patients with and without DM according to the type of ACS are presented in Table 1. Angiographic and procedural variables are listed in Table 2.

The rate of mortality at 1 year was $13.4 \%$ in diabetic patients with STEMI, $10.3 \%$ in diabetic patients with
NSTE-ACS, $6.4 \%$ in nondiabetic patients with STEMI, and $4.4 \%$ in nondiabetic patients with NSTE-ACS ( $p<0.001$ across the groups; Figure 1). The instantaneous risk of death across the 4 groups is shown in the Supplementary Figure 1. Compared with nondiabetic patients, DM was associated with approximately a twofold higher risk of mortality in both STEMI (HR adj $2.17,95 \%$ CI 1.67 to 2.81 , $\mathrm{p}<0.001)$ and NSTE-ACS cohorts in adjusted analyses $\left(\mathrm{HR}_{\mathrm{adj}} 2.39,95 \%\right.$ CI 1.93 to $3.00, \mathrm{p}<0.001$; Table 3$)$. Unadjusted analyses are summarized in the Supplementary Table 1.

Within both diabetic and nondiabetic populations, STEMI compared to NSTE-ACS was associated with a higher risk of early versus late events, resulting in a significant interaction of ACS type for death, cardiac death, target lesion revascularization, and target vessel revascularization (Table 4). The Kaplan-Meier curves for all-cause mortality with the landmark at 30 days are shown in Figure 2. Among diabetic patients, STEMI was associated with a higher risk of early mortality $\left(\mathrm{HR}_{\mathrm{adj}} 2.31,95 \% \mathrm{CI}\right.$ 1.52 to $3.54, p<0.001)$, but this pattern tended to reverse during the late period $\left(\mathrm{HR}_{\text {adj }} 0.75,95 \% \mathrm{CI} 0.47\right.$ to 1.21 , $\left.\mathrm{p}=0.24 ; \mathrm{P}_{\text {int }}<0.001\right)$. A similar course was observed among nondiabetic patients, in whom the risk of mortality of STEMI versus NSTE-ACS was greater during the early $\left(\mathrm{HR}_{\mathrm{adj}} 2.20,95 \% \mathrm{CI} 1.57\right.$ to $\left.3.04, \mathrm{p}<0.001\right)$ compared with the late period ( $\mathrm{HR}_{\text {adj }} 1.20,95 \% \mathrm{CI} 0.87$ to $1.63, \mathrm{p}=0.26$; $\left.\mathrm{P}_{\text {int }}<0.001\right)$. At variance with the described pattern, the risk of early and late definite stent thrombosis was increased by more than twofold in both diabetic and nondiabetic patients with STEMI compared with NSTE-ACS.

In the analysis of risk estimates between diabetic and nondiabetic subgroups (Table 5), there was no significant 
Table 4

Clinical outcomes throughout 1 year

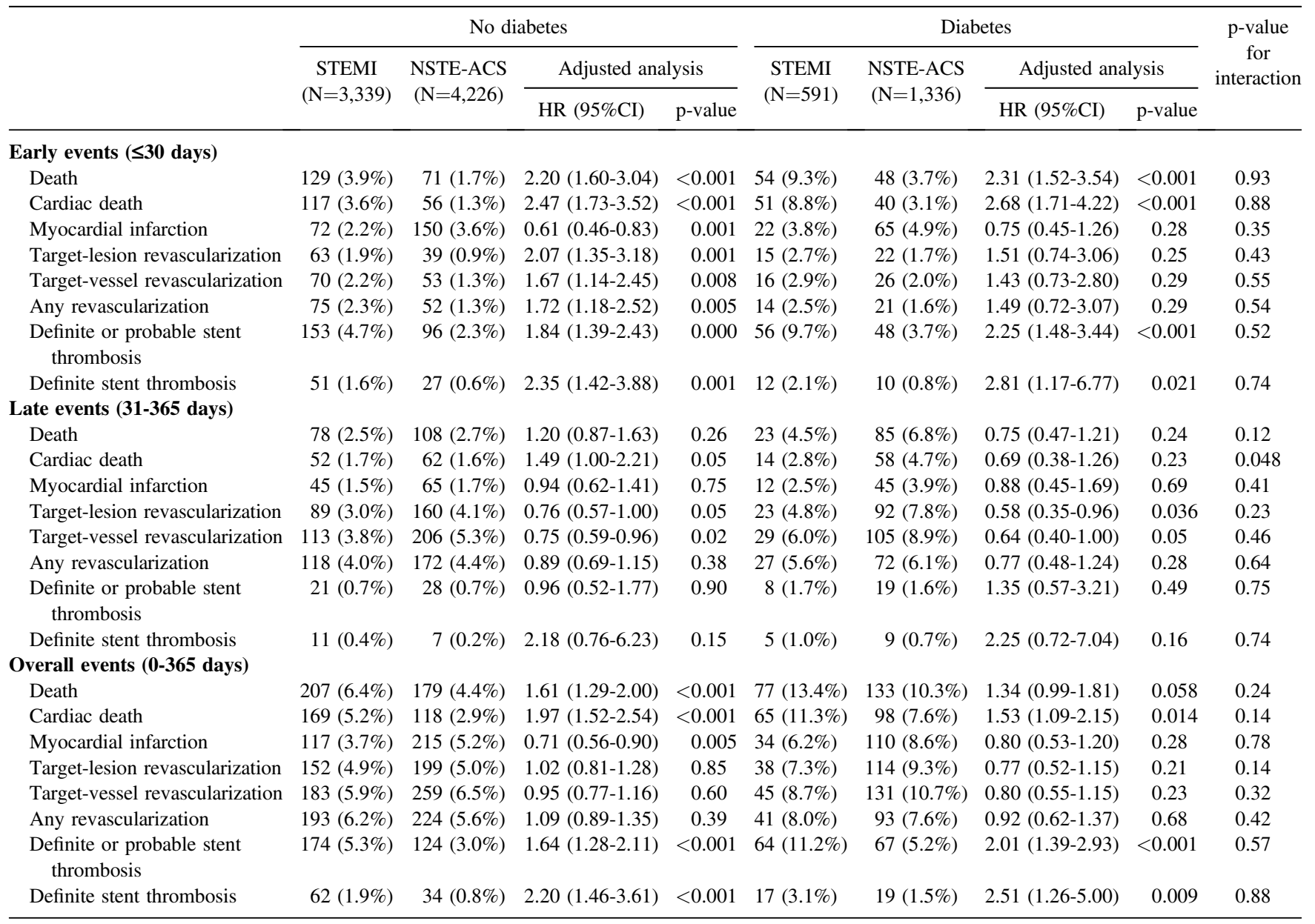

A

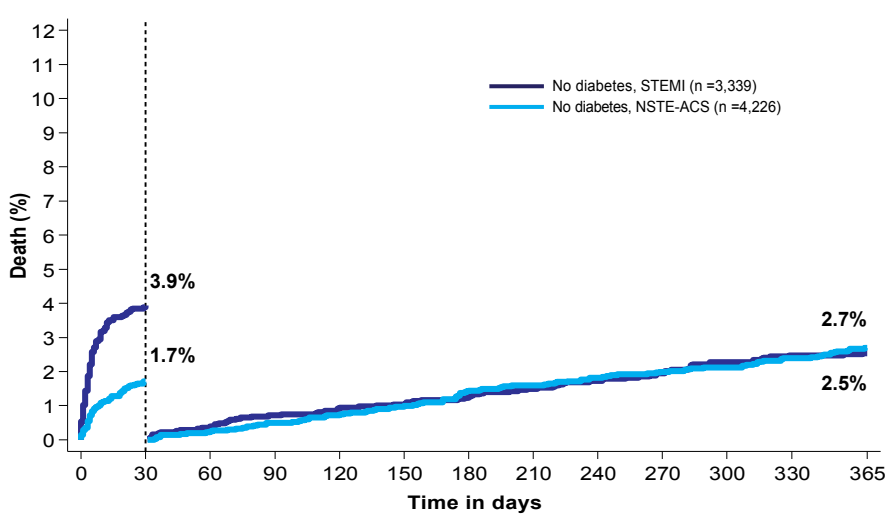

B

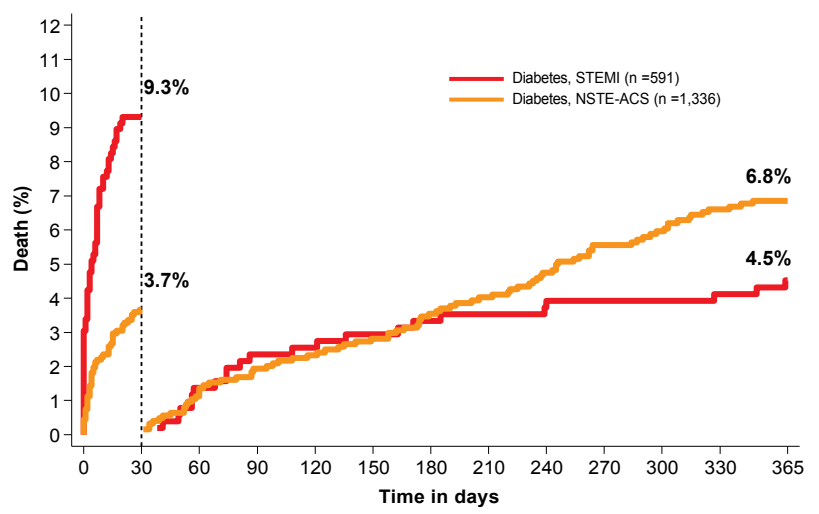

Figure 2. Kaplan-Meier time-to-event curves for all-cause death at 1 year with landmark analysis set at 30 days (Panel A, within nondiabetic and Panel B, within diabetic patients).

interaction throughout the follow-up with the exception of late cardiac mortality associated with STEMI versus NSTEACS that was higher in nondiabetic compared with diabetic patients $\left(\mathrm{P}_{\mathrm{int}}=0.048\right)$. Consistent results were observed in patients treated with new-generation drug-eluting stents (Supplementary Table 2).

\section{Discussion}

We investigated the impact of diabetic status and type of ACS on the temporal distribution of adverse events among 9,492 patients undergoing PCI. The principal findings of the study can be summarized as follows: 
Table 5

Early versus late events according to the type of acute coronary syndrome

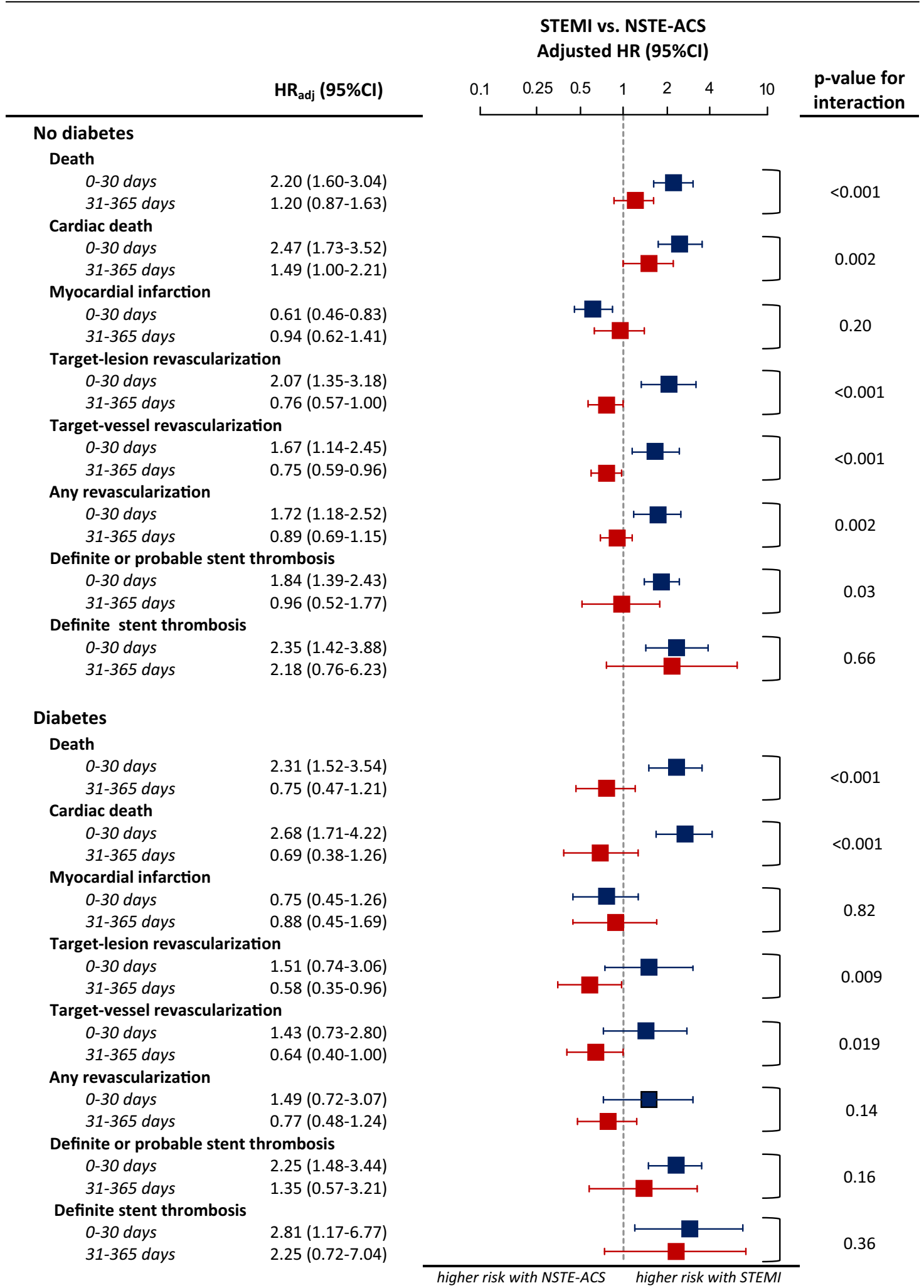


1) Patients with DM had a twofold increased risk of mortality compared with nondiabetic patients in the setting of STEMI and NSTE-ACS at 1 year of follow-up.

2) Compared with NSTE-ACS, STEMI was associated with impaired early outcomes increasing the risk of mortality twofold within the first 30 days in both diabetic and nondiabetic patients. Patients with STEMI, irrespective of their diabetic status, have a higher risk of definite stent thrombosis and repeat revascularization compared with NSTE-ACS patients.

3) Despite the high event rate, the temporal distribution of adverse events related to the type of ACS throughout the follow-up was similar between diabetic and nondiabetic patients.

Improving the knowledge about the prognosis of diabetic patients with ACS remains an important prerequisite to improve future care and management. ${ }^{21}$ Our study corroborates previous observations regarding the independent association of DM with mortality in the setting of ACS, by showing a twofold greater risk of death in patients with DM who presented with STEMI or NSTE-ACS in a large cohort of patients undergoing contemporary management including PCI. We observed that the rates of mortality at 1 year are highest among diabetic patients with STEMI followed by diabetic patients with NSTE-ACS. In the largest study available on this issue, including 62,036 patients with ACS enrolled across 11 randomized trials, the 1-year mortality was highest in diabetic patients with STEMI (13.2\%) and lowest in nondiabetic patients with NSTE-ACS $(3.1 \%){ }^{6}$ The mortality of diabetic patients with NSTE-ACS approached that of STEMI patients without DM $(7.2 \%$ and $8.1 \%$, respectively). ${ }^{6}$ This study pooled trials conducted between 1997 and 2006 in which myocardial revascularization was performed $<30 \%$ of cases. ${ }^{6}$ We observed similar rates of 1-year mortality in STEMI patients with DM (13.4\%) and in NSTE-ACS patients without DM (4.4\%). However, NSTE-ACS patients with DM had a higher risk of mortality than STEMI patients without DM (10.3\% vs $6.4 \%)$. This underscores that despite the improvements in the treatment of ACS and the routine adoption of myocardial revascularization, DM continues to confer a worse prognosis with high mortality rates exceeding $10 \%$ in the setting of both STEMI and NSTE-ACS at 1 year. Although we cannot exclude selection and entry bias due to the inclusion of ACS patients undergoing PCI, the present patient population may be more reflective of contemporary clinical practice in view of the all-comer design of included studies. Along with a higher risk of mortality, patients with STEMI had also an increased risk of stent thrombosis and repeat revascularization during the early period after STEMI, and this finding was also observed in diabetic patients. In contrast, the risk of late ( $>30$ days) target lesion and target vessel revascularization was higher in both diabetic and nondiabetic patients with NSTE-ACS compared with STEMI patients. It may be possible that this inverse pattern in the risk of repeat revascularization procedures was driven by increased rates of stent thrombosis during the early period of STEMI and by a higher risk of restenosis during the late phase of NSTE-ACS patients who had a higher frequency of multivessel interventions at baseline. Another finding of this study is the lacking impact of DM on the timing of adverse events after ACS. Indeed, the temporal distribution of fatal and nonfatal adverse events of ACS patients with DM was comparable to that of the nondiabetic counterpart. Although the temporal variation of adverse events in the ACS setting has been widely studied, ${ }^{3-5}$ our observations, focusing on diabetic patients, may have important therapeutic implications for the care of this highrisk population. ${ }^{22}$ In this regard, the increased risk of stent thrombosis in diabetic patients with STEMI, with rates of definite stent thrombosis exceeding $2 \%$ during the early period, underscores the need for a widespread adoption of potent antiplatelet agents in this patient subset. ${ }^{23,24}$ The results of this study have to be interpreted in view of several limitations. First, this is a retrospective analysis although all data were prospectively collected, uniformly recorded, and events independently adjudicated. Second, we included only ACS patients undergoing PCI; and therefore, our findings could not be extrapolated to ACS patients managed without revascularization. Although this may have introduced some bias, myocardial revascularization represents a treatment modifier, which has been identified as confounder in previous analyses. Third, our definition of DM did not include patients who were diagnosed during or after the index hospitalization. Nevertheless, this definition was not biased by altered glucose levels that may occur particularly during STEMI. Fourth, data regarding the type and duration of DM, as well as admission glucose and glycated hemoglobin levels were not available for the analyses. Finally, several studies included into this analysis no longer reflect contemporary clinical practice, particularly with respect to the antithrombotic therapy. ${ }^{25}$

\section{Disclosures}

Dr. Piccolo has received a research grant from the Veronesi Foundation (Italy). Dr. Jüni is an unpaid steering committee or statistical executive committee member of trials funded by Abbott Vascular, Biosensors, Medtronic, and St. Jude Medical. Dr. Windecker has received research grants to the Institution from Biotronik and St Jude, and speaker fees from Astra Zeneca, Eli Lilly, Abbott, Medtronic, and Biotronik. All other authors have no conflicts of interest to disclose.

1. Ndrepepa G, Kastrati A. Bleeding complications in patients undergoing percutaneous coronary interventions: current status and perspective. Coron Artery Dis 2014;25:247-257.

2. Gregg EW, Li Y, Wang J, Burrows NR, Ali MK, Rolka D, Williams DE, Geiss L. Changes in diabetes-related complications in the United States, 1990-2010. N Engl J Med 2014:370:1514-1523.

3. Chan MY, Sun JL, Newby LK, Shaw LK, Lin M, Peterson ED, Califf RM, Kong DF, Roe MT. Long-term mortality of patients undergoing cardiac catheterization for ST-elevation and non-ST-elevation myocardial infarction. Circulation 2009;119:3110-3117.

4. Park HW, Yoon CH, Kang SH, Choi DJ, Kim HS, Cho MC, Kim YJ, Chae SC, Yoon JH, Gwon HC, Ahn YK, Jeong MH; KAMIR/KorMI 
Registry. Early- and late-term clinical outcome and their predictors in patients with ST-segment elevation myocardial infarction and non-STsegment elevation myocardial infarction. Int J Cardiol 2013;169: $254-261$.

5. Savonitto S, Ardissino D, Granger CB, Morando G, Prando MD, Mafrici A, Cavallini C, Melandri G, Thompson TD, Vahanian A, Ohman EM, Califf RM, Van de Werf F, Topol EJ. Prognostic value of the admission electrocardiogram in acute coronary syndromes. JAMA 1999;281:707-713.

6. Donahoe SM, Stewart GC, McCabe CH, Mohanavelu S, Murphy SA, Cannon CP, Antman EM. Diabetes and mortality following acute coronary syndromes. JAMA 2007;298:765-775.

7. Franklin K, Goldberg RJ, Spencer F, Klein W, Budaj A, Brieger D, Marre M, Steg PG, Gowda N, Gore JM; GRACE Investigators. Implications of diabetes in patients with acute coronary syndromes. The Global Registry of Acute Coronary Events. Arch Intern Med 2004;164: $1457-1463$.

8. Malmberg K, Yusuf S, Gerstein HC, Brown J, Zhao F, Hunt D, Piegas L, Calvin J, Keltai M, Budaj A. Impact of diabetes on long-term prognosis in patients with unstable angina and non-Q-wave myocardial infarction: results of the OASIS (Organization to Assess Strategies for Ischemic Syndromes) registry. Circulation 2000;102:1014-1019.

9. Piccolo R, Galasso G, Iversen AZ, Eitel I, Dominguez-Rodriguez A, Gu YL, de Smet BJ, Mahmoud KD, Abreu-Gonzalez P, Trimarco B, Thiele H, Piscione F. Effects of baseline coronary occlusion and diabetes mellitus in patients with ST-segment elevation myocardial infarction undergoing primary percutaneous coronary intervention. Am J Cardiol 2014;114:1145-1150.

10. Franzone A, Pilgrim T, Heg D, Roffi M, Tuller D, Vuilliomenet A, Muller O, Cook S, Weilenmann D, Kaiser C, Jamshidi P, Raber L, Stortecky S, Wenaweser P, Juni P, Windecker S. Clinical outcomes according to diabetic status in patients treated with biodegradable polymer sirolimus-eluting stents versus durable polymer everolimuseluting stents: prespecified subgroup analysis of the BIOSCIENCE trial. Circ Cardiovasc Interv 2015;8:e02319.

11. Windecker S, Remondino A, Eberli FR, Juni P, Raber L, Wenaweser P, Togni M, Billinger M, Tuller D, Seiler C, Roffi M, Corti R, Sutsch G, Maier W, Luscher T, Hess OM, Egger M, Meier B. Sirolimus-eluting and paclitaxel-eluting stents for coronary revascularization. $N$ Engl $J$ Med 2005;353:653-662.

12. Windecker S, Serruys PW, Wandel S, Buszman P, Trznadel S, Linke A, Lenk K, Ischinger T, Klauss V, Eberli F, Corti R, Wijns W, Morice MC, di Mario C, Davies S, van Geuns RJ, Eerdmans P, van Es GA, Meier B, Juni P. Biolimus-eluting stent with biodegradable polymer versus sirolimus-eluting stent with durable polymer for coronary revascularisation (LEADERS): a randomised non-inferiority trial. Lancet 2008:372:1163-1173.

13. Serruys PW, Silber S, Garg S, van Geuns RJ, Richardt G, Buszman PE, Kelbaek H, van Boven AJ, Hofma SH, Linke A, Klauss V, Wijns W, Macaya C, Garot P, DiMario C, Manoharan G, Kornowski R, Ischinger T, Bartorelli A, Ronden J, Bressers M, Gobbens P, Negoita M, van Leeuwen F, Windecker S. Comparison of zotarolimus-eluting and everolimus-eluting coronary stents. N Engl J Med 2010;363:136-146.

14. Zbinden R, Piccolo R, Heg D, Roffi M, Kurz DJ, Muller O, Vuilliomenet A, Cook S, Weilenmann D, Kaiser C, Jamshidi P, Franzone A,
Eberli F, Juni P, Windecker S, Pilgrim T. Ultrathin strut biodegradable polymer sirolimus-eluting stent versus durable-polymer everolimuseluting stent for percutaneous coronary revascularization: 2-Year results of the BIOSCIENCE trial. J Am Heart Assoc 2016;5:e03255.

15. Valgimigli M, Campo G, Monti M, Vranckx P, Percoco G, Tumscitz C, Castriota F, Colombo F, Tebaldi M, Fuca G, Kubbajeh M, Cangiano E, Minarelli M, Scalone A, Cavazza C, Frangione A, Borghesi M, Marchesini J, Parrinello G, Ferrari R; Prolonging Dual Antiplatelet Treatment After Grading Stent-Induced Intimal Hyperplasia Study (PRODIGY) Investigators. Short- versus long-term duration of dualantiplatelet therapy after coronary stenting: a randomized multicenter trial. Circulation 2012;125:2015-2026.

16. Pilgrim T, Heg D, Roffi M, Tuller D, Muller O, Vuilliomenet A, Cook S, Weilenmann D, Kaiser C, Jamshidi P, Fahrni T, Moschovitis A, Noble S, Eberli FR, Wenaweser P, Juni P, Windecker S. Ultrathin strut biodegradable polymer sirolimus-eluting stent versus durable polymer everolimus-eluting stent for percutaneous coronary revascularisation (BIOSCIENCE): a randomised, single-blind, non-inferiority trial. Lancet 2014;384:2111-2122.

17. Vranckx P, Cutlip DE, Mehran R, Kint PP, Silber S, Windecker S, Serruys PW. Myocardial infarction adjudication in contemporary all-comer stent trials: balancing sensitivity and specificity. Addendum to the historical MI definitions used in stent studies. EuroIntervention 2010:5:871-874.

18. Cutlip DE, Windecker S, Mehran R, Boam A, Cohen DJ, van Es GA, Steg PG, Morel MA, Mauri L, Vranckx P, McFadden E, Lansky A, Hamon M, Krucoff MW, Serruys PW, Academic Research C. Clinical end points in coronary stent trials: a case for standardized definitions. Circulation 2007:115:2344-2351.

19. Harris PA, Taylor R, Thielke R, Payne J, Gonzalez N, Conde JG. Research electronic data capture (REDCap)-a metadata-driven methodology and workflow process for providing translational research informatics support. J Biomed Inform 2009;42:377-381.

20. Lambert PC, Royston P. Further development of flexible parametric models for survival analysis. Stata J 2009;9:265-290.

21. Roffi M, Angiolillo DJ, Kappetein AP. Current concepts on coronary revascularization in diabetic patients. Eur Heart J 2011;32: $2748-2757$.

22. Armstrong EJ, Rutledge JC, Rogers JH. Coronary artery revascularization in patients with diabetes mellitus. Circulation 2013;128: $1675-1685$.

23. Piccolo R, Eitel I, Galasso G, Iversen AZ, Gu YL, DominguezRodriguez A, de Smet BJ, Mahmoud KD, Abreu-Gonzalez P, Thiele H, Piscione F. Intracoronary abciximab in diabetic patients with STsegment elevation myocardial infarction undergoing primary percutaneous coronary intervention. Vascul Pharmacol 2015;73:32-37.

24. Piccolo R, Di Gioia G, Niglio T, D’Anna C, De Rosa R, Strisciuglio T, Bevilacqua M, Piscione F, Cirillo P, Galasso G. Pharmacotherapeutic considerations for the use of prasugrel and ticagrelor to reduce stent thrombosis in patients with acute coronary syndrome. Angiology 2014;65:130-136.

25. Piccolo R, Windecker S. Dual antiplatelet therapy in percutaneous coronary intervention: a tale of 2 decades with new perspectives in the era of new-generation drug-eluting stents. Circ Cardiovasc Interv 2016;9:e003587. 